\title{
EFEITO REPELENTE DO ÓLEO ESSENCIAL DO GÊNERO PIPER SOBRE A LARVA DA ESPÉCIE DE CARRAPATO RHIPICEPHALUS SANGUINEUS
}

\author{
AUTOR: BEATRIZ PORTO DE SANTANA \\ CO-AUTOR: GISELE LOPES DE OLIVEIRA \\ CO-AUTOR: RODRIGO GUIMARAES DE DEUS \\ CO-AUTOR/ORIENTADOR: MARCIA NUNES BANDEIRA RONER
}

\begin{abstract}
Resumo: Os carrapatos são artropodes ectoparasita que necessitam de sangue para se alimentar sendo seres hematofágos. Devido a isso podem ser encontrados no mundo todo parasitando diferentes hospedeiros. Nos ambientes urbanos e rurais o Rhipicephalus sanguineus encontra-se parasitando o cão, o Rhipicephalus (Boophilus) microplus parasitando os bovinos e o Amblyomma cajennense, os equinos. Para o controle desses parasitas são utilizados acaricidas de origem vegetal que são menos agressivos, tanto para o homem, animais, quanto para o meio ambiente. Atualmente tem utilizado acaricidas com óleo essencial que são oriundos das plantas. Os objetivos da pesquisa foi realizar um levantamento bibliográfico dos trabalhos que utilizaram plantas no controle de carrapato, além de identificar os principais constituintes encontrados nos óleos essenciais para o controle desses parasitas. A pesquisa foi realizada na base de dados do Google School, Scielo e Periódicos CAPES, com termos específicos. No total foram utilizadas 16 fontes bibliográficas e com as informações levantadas, foi gerado um banco de dados. Os resultados mostraram as principais espécies estudadas de carrapatos, bem como, as espécies de plantas mais usadas nos testes e os princípios ativos encontrados nas plantas. A espécie mais estudada do carrapato foi o Rhipicephalus (Boophilus) microplus e a planta mais encontrada foi a Corymbia citriodora.
\end{abstract}

Palavras-chave: Carrapatos, óleo essencial, plantas. 